\title{
Polyacrolein with Microspherical Structure Obtained by Radiation-Initiation and Base Catalysis
}

\author{
Ali USANMAZ and Recep Dursun DoGan \\ Department of Chemistry, Middle East Technical University, \\ Ankara, Turkey
}

(Received August 4, 1989)

\begin{abstract}
Acrolein was polymerized by radiation and base catalyzed condensation. Radiation polymerization was carried in bulk form under vacuum and air atmosphere at several temperatures. The conversion reached close to $100 \%$, and polymers were free flowing white powders up to $5 \%$ conversion at $-15^{\circ} \mathrm{C}$, up to $80 \%$ at higher temperatures and up to $10 \%$ in air atmosphere polymerization. Radiation polymerization from aqueous solutions of various $\mathrm{pH}$ and from acetone solutions gave white powder polymers with limiting conversions ranging from 10 to $18 \%$ depending on the solution type or $\mathrm{pH}$. The conversion at $\mathrm{pH}$ between 1,5 to 8 gave minimum $\mathrm{pH}$ of 5 to 6 . The base catalyzed polymerization at $\mathrm{pH}$ of 9 to 12 gave white powdered polymers changing to a yellowish colour with increase of $\mathrm{pH}$. The limiting conversion was about $14 \%$. The nature of repeating units in the polymer chains was studied by IR and thermogravimetry. The polymers contained different repeating units randomly, and the aldehyde content was higher for radiation polymerization than base catalyzed polymerization. A scanning electron microscope investigation showed the powder polymers to have microspherical structures of various size depending on polymerization conditions.
\end{abstract}

KEY WORDS Radiation / Acrolein / Microsphere Structure / Aldehyde Groups / Thermogravimetric Analysis / Base Catalysis / Microscopy /

Acrolein (I) can be polymerized by addition reactions to give polymers containing different types of units. The type of addition (1, 2 or 3, 4 additions) depends on the polymerization conditions and the molecular structure of the monomer. At room temperature, the molecule is in the trans form, but can change to the cis form $^{1}$ at other temperatures. Therefore, the polymerization mechanism is very complicated and usually gives insoluble polymers.

The polymerization and polymer properties of acrolein became very important after it was realized that proteins such as antibodies and enzymes can be immobilized on the surface of polyacrolein (PA) microspheres without an activating step. $^{2-5}$ The polymerizations of acrolein by chemical catalysts and radiation have been studied under various conditions. ${ }^{6-13}$ Margel et al. ${ }^{3,4,7,10,11}$ polymerized acrolein in an aqueous solution, containing surfactants, to obtain polymers with microspherical structure of various sizes. Kumakura et al. ${ }^{12}$ studied the effects of temperature and additives on polymer yield and microspherical size in the radiation induced polymerization of acrolein. The structure of the polymer obtained from aqueous solutions, in the presence of additives, by various intiators has been studied using IR and NMR methods. ${ }^{8,9,11,15,16}$ Hunter and Forbes $^{14}$ investigated the molecular structure of polyacrolein obtained by redox catalysts by fractional dehydration and GC.

The PA obtained by chemical catalysts will contaminate the product making it unsuitable for biomedical use. Therefore, the best method of polymerization is radiation initiation for the desired product. However, previous works failed to investigate the following points: (a) 
Microspherical structures are reported in the initial stage of acrolein polymerization in an aqueous solution containing additives. In this case, the polymer yield is low, there will be some contamination and production cost becomes high. Therefore, the production of microspherical PA in bulk polymerization at various conversions has to be investigated; (b) The chain structure of insoluble polymers has only been studied by spectroscopic (mostly IR) methods which are insufficient for reliable results. Also the structure of polymers obtained under various conditions has not been compared; (c) The monomer polymerizes by base condensation reaction. Therefore, the $\mathrm{pH}$ effect in radiation-initiation on polymerization conversion and nature of product in an aqueous solution should also be investigated and compared with base catalyzed polymerization; (d) The temperature effects on polymer yield has been investigated, but the effects on microspherical formation and molecular structure has not yet been studied; (e) It has been shown that the polymerization rate is higher for radiation-initiated polymerization in aqueous solution than in other organic solutions, but the difference between the types of polymers has not been reported.

In this work, polymerization was carried out in bulk, in aqueous solutions of different $\mathrm{pH}$ and in acetone by radiation as well by base catalysts at various $\mathrm{pH}$ to explain (a) the kinetics of polymerization under various conditions, (b) the dependence of microsphere formation on conversion and temperature in radiation polymerization of the bulk material, (c) the difference of radiation polymerization of acrolein in bulk and in solution in terms of conversion and microsphere formation, and (d) the repeating structural units in polymer chains obtained under various conditions. The polymer structures were studied by IR, thermogravimetry (dehydration and DSC) and electron scanning microscope (SEM).

$$
\underset{1}{\mathrm{CH}_{2}}=\underset{2}{\mathrm{C}} \mathrm{H}-\underset{3}{\mathrm{C}} \mathrm{H}=\underset{4}{\mathrm{O}}
$$

(I)

\section{EXPERIMENTAL}

Reagent quality acrolein "Aldrich" was purified by distillation. The fraction collected at $52 \pm 0.5^{\circ} \mathrm{C}$ was used for polymerization immediately after purification. Water was triple distilled. Other organic solvents were purified by distillation. $\mathrm{NaOH}, \mathrm{HCl}$ and $\mathrm{Na}_{2} \mathrm{CO}_{3}$ were "Merck" grade and used without further purification.

Solutions of standard $\mathrm{pH}$ were prepared from $0.2-\mathrm{M} \mathrm{HCl}, 0.2-\mathrm{M} \mathrm{Na} \mathrm{CO}_{3}$ and $10 \%$ $(\mathrm{w} / \mathrm{v}) \mathrm{NaOH}$ alone or in combinations. $\mathrm{pH}$ was measured by a $\mathrm{pH}$-meter throughout the polymerizations.

Two $\mathrm{ml}$ of pure monomer or $3 \mathrm{ml}$ of a solution (aqueous or acetone) containing 20\% $(\mathrm{v} / \mathrm{v})$ acrolein were placed in an irradiation tube of pyrex-glass and connected to a high vacuum system. Sample tubes were degassed by three cycles of freeze-thawing and under reduced pressure $\left(10^{-4}-10^{-6} \mathrm{mmHg}\right)$ then sealed off and placed in Co-60 gamma source with a dose rate of $1 \times 10^{-5} \mathrm{rad} \cdot \mathrm{h}^{-1}$ for the desired time. The polymer precipitated as it formed in the sample tube. The tubes were broken after irradiation and the polymer was treated with a large volume of methanol. The precipitate was filtered and dried in vacuo at $50{ }^{\circ} \mathrm{C}$. The conversion was determined gravimetrically. The polymerizations in air were done by the same technique but without evacuating the sample tubes.

Polymerization by base catalysis was carried in a buffer solution made from $\mathrm{CO}_{3}{ }^{2-} / \mathrm{HCO}_{3}{ }^{-}$. Monomer was added to the buffer solution slowly while stirring continously. The final volume in each case was $5 \mathrm{ml}$ containing $1 \mathrm{ml}$ monomer. Polymerization reached a limiting conversion in about two hours. The polymer was precipitated and excess methanol was added for complete precipitation. The polymer 
was separated by filtration and dried in vacuo at $50^{\circ} \mathrm{C}$ to constant weight.

IR spectra were taken with a "Perkin-Elmer, 1430 ratio recording" IR spectrophotometer using $\mathrm{KBr}$ pellets. The "S4-10 Doublescan type Cambridge Stereoscan" scanning electron microscope was used to take a micrograph of the polymer samples. Thermal analysis was carried on a "DSC-4 Differential Scanning Calorimeter" (Perkin Elmer).

\section{RESULTS AND DISCUSSION}

\section{Polymerization of Acrolein Initiated by Gam- ma-Ray}

Acrolein was polymerized by radiationinitiation in vacuo at temperatures of $-15,0$, and $25^{\circ} \mathrm{C}$. The conversion against irradiation time is plotted in Figure 1. The curves are " $\mathrm{S}$ " shaped and rate increases with increasing temperature. In all three cases, the polymerization reached $100 \%$ conversion. The break in the rate at about $60 \%$ conversion for reaction at $25^{\circ} \mathrm{C}$ is quite unusual for radiation-initiated polymerization. The reason may be factors such as conformational change of monomer (1), the size of microspheres changing the viscosity of the reaction medium (9), the dependence of rate constants for the vinyl and aldehyde groups on temperature. Polymers were white powders but changed to a gel form after $5 \%$ conversion at $-15^{\circ} \mathrm{C}$ and after $80 \%$

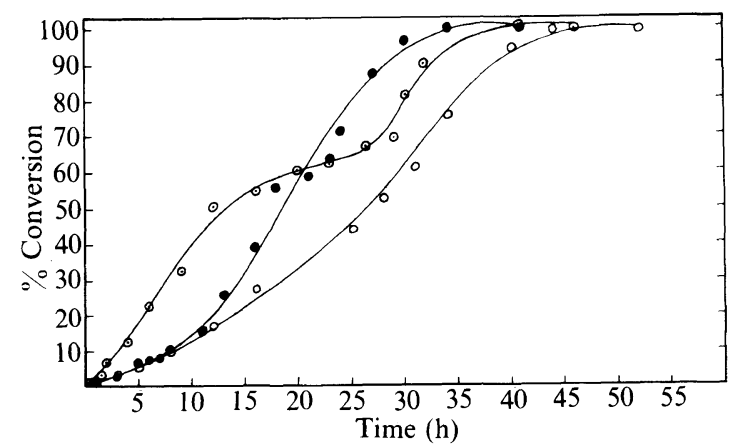

Figure 1. Radiation-initiated bulk polymerization of acrolein under vacuum at (a) $\mathrm{O},-15^{\circ} \mathrm{C}$, (b) $0,0^{\circ} \mathrm{C}$, and (c) $\odot, 25^{\circ} \mathrm{C}$. conversion at $25^{\circ} \mathrm{C}$ and $0^{\circ} \mathrm{C}$. The polymers were insoluble in common solvents, but became swollen and eventually decomposed in a strong basic medium. They were resistant to acidic solutions.

Acrolein was polymerized by radiation in air at $25^{\circ} \mathrm{C}$ and $-15^{\circ} \mathrm{C}$. The conversion against time is plotted in Figure 2. The rate of polymerization increased with increasing temperature. However, the rates in this case are lower than those for polymerization in vacuum at corresponding temperatures. This shows the retarding effect of oxygen. The break observed in the polymerization curve at $25^{\circ} \mathrm{C}$ in vacuo is not found for the reaction in air. The polymers are free-flowing white powders at lower conversion, but change to gels above $10 \%$ conversion. This can be used as evidence of the break in the curve of Figure 1 at $25^{\circ} \mathrm{C}$ being related to microsphere size rather than to other factors. The absence of a break for polymerization at $25^{\circ} \mathrm{C}$ in air may be due to the gel structure and absence of microsphere formation. However, in vacuum polymerization, the microspheres are small enough to be dispersed in the solution instead of precipitating; the viscosity will be higher and therefore the rate smaller due to slower diffusion of monomer molecules. The size of microspheres reach a size sufficient to precipitate above $70 \%$ conversion and therefore rate is increased again. When polymerization was carried out in

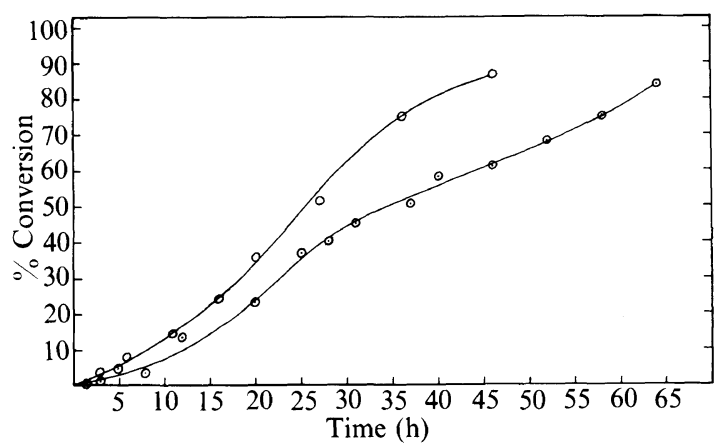

Figure 2. Radiation-initiated bulk polymerization of acrolein open to air atmosphere at (a) $\odot,-15^{\circ} \mathrm{C}$ and (b) $\bigcirc, 25^{\circ} \mathrm{C}$. 
air the polymer stuck to the glass surface at $80-90 \%$ conversions and caused the glass tube to break. Therefore, it became impossible to continue the polymerization up to $100 \%$ conversion. (This property of the polymer will be investigated in another work.)

\section{Polymerization of Acrolein in Solution Initiated by Gamma-Rays}

Acrolein was polymerized in aqueous and acetone solutions by gamma-rays initiation. The solubility of acrolein in water is about $20 \%(\mathrm{v} / \mathrm{v})$. Therefore, polymerizations were carried out in $20 \%(\mathrm{v} / \mathrm{v})$ aqueous solutions at various $\mathrm{pH}$. In aqueous solutions we hoped to obtain a polymer with a microsphere structure containing larger numbers of free aldehyde groups due to the proton attack on aldehyde

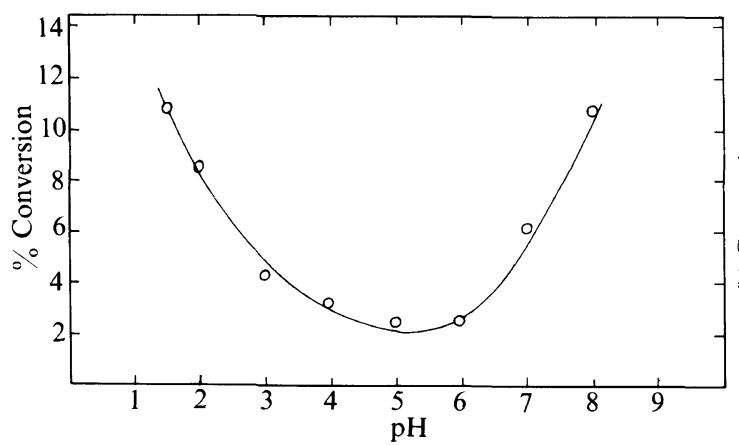

Figure 3. Polymerization of acrolein in $20 \%(\mathrm{v} / \mathrm{v})$ aqueous solution at different $\mathrm{pH}$ values by $5 \mathrm{~h}$ irradiation under vacuum at $25^{\circ} \mathrm{C}$.

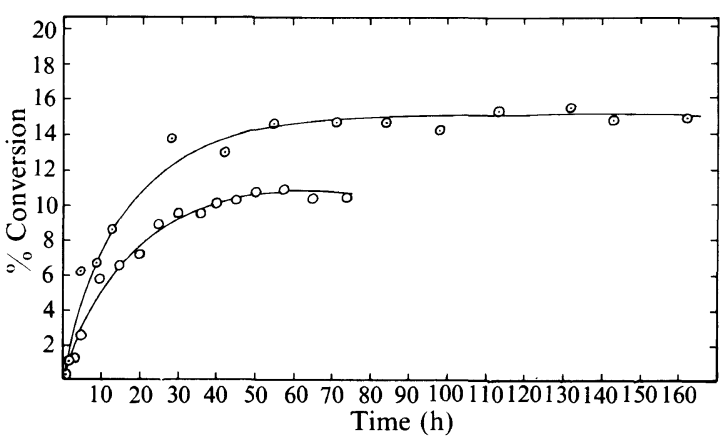

Figure 4. Radiation-initiated polymerization of acrolein in $20 \%(\mathrm{v} / \mathrm{v})$ aqueous solution under vacuum at $25^{\circ} \mathrm{C}$ and $\mathrm{pH}$ of (a) $\bigcirc, 5$ and (b) to prevent acetal formation as suggested by Andreeva et al. $^{15}$

Polymerizations of acrolein in aqueous solutions at $\mathrm{pH}$ between $1.5-8$ were carried out by radiation-initiation in vacuo for $5 \mathrm{~h}$. The plot of conversions against $\mathrm{pH}$ is shown in Figure 3. The conversion is $10.8 \%$ at $\mathrm{pH} 1.5$ and decreased to about $2.5 \%$ at $\mathrm{pH} 5$ to 6 , then increased again to $10.8 \%$ at $\mathrm{pH} 8$. When the $\mathrm{pH}$ increased further the monomer polymerized by catalysis without irradiation. The polymers obtained in all cases were in the form of free-flowing white powders.

The polymerizations in aqueous solutions at $\mathrm{pH}$ of 5 and 7 were carried out for various irradiation times in vacuo at $25^{\circ} \mathrm{C}$. The plot of conversion against irradiation time are givein in Figure 4. The conversion increased slowly

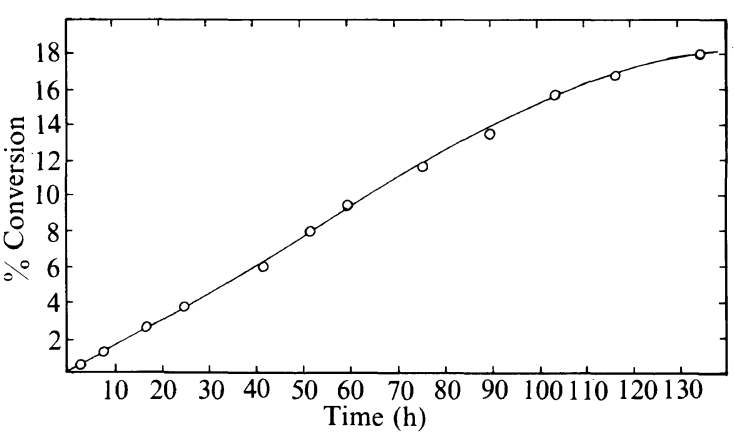

Figure 5. Radiation-initiated polymerization of acrolein in $20 \%(\mathrm{v} / \mathrm{v})$ acetone solution under vacuum at $25^{\circ} \mathrm{C}$.

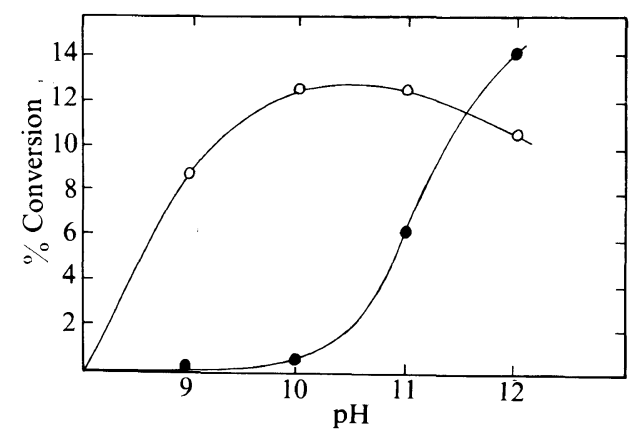

Figure 6. Polymerization of acrolein open to air in various $\mathrm{pH}$ of aqueous solutions at (a),$-30^{\circ} \mathrm{C}$ and (b) $\bigcirc, 25^{\circ} \mathrm{C}$. 
with irradiation time up to a limiting conversion of about $10 \%$ for $\mathrm{pH} 5$ and $15 \%$ for $\mathrm{pH}$ 7. The colour of the polymer obtained at pH 7 became yellow after about $10 \mathrm{~h}$ irradiation and the intensity of colour increased with irradiation time.

The $\mathrm{pH}$ of the solution was adjusted by $\mathrm{Na}_{2} \mathrm{CO}_{3}$ buffer solutions and also without $\mathrm{Na}_{2} \mathrm{CO}_{3}$ using $\mathrm{HCl}$ or $\mathrm{NaOH}$ alone to check the effect of $\mathrm{CO}_{3}{ }^{2-}-\mathrm{HCO}_{3}{ }^{-}$in the polymerization medium. No difference could be observed and it was concluded that the presence of carbonates has no apparent effect.

Polymerization in $20 \%(\mathrm{v} / \mathrm{v})$ acetone solution was also carried out to obseve the effects of dilution without protonation of aldehyde groups. A plot of converstion against time is given in Figure 5. The conversion increases almost linearly with irradiation time up to about the limiting conversion. The rate of polymerization is less than that in an aqueous solution. However, the limiting conversion of about $18 \%$, is higher than that for a neutral aqueous solution. The polymers obtained at all irradiation times are in the form of freeflowing white powders.

\section{Polymerization of Acrolein by Base Catalysis}

Acrolein in an aqueous solution polymerized with $\mathrm{NaOH}$ when the $\mathrm{pH}$ of the solution exceeded 8. Polymerizations at $\mathrm{pH} 9$ to 12 were carried at $-30^{\circ} \mathrm{C}$ and $25^{\circ} \mathrm{C}$. The conversion against $\mathrm{pH}$ is plotted in Figure 6. The conversion at $\mathrm{pH}$ of 9 and 10 are very small at $-30^{\circ} \mathrm{C}$, but increased sharply after $\mathrm{pH} 10$ and reached about $14 \%$ at $\mathrm{pH} 12$. However, at $25^{\circ} \mathrm{C}$ conversion increased sharply at $\mathrm{pH} 9$ and reached a maximum of about $13 \%$ at $\mathrm{pH}$ 11 , then decreased to about $10 \%$ at $\mathrm{pH} 12$. The polymers were white powders at $\mathrm{pH} 9$, but changed to yellow with increasing intensi-

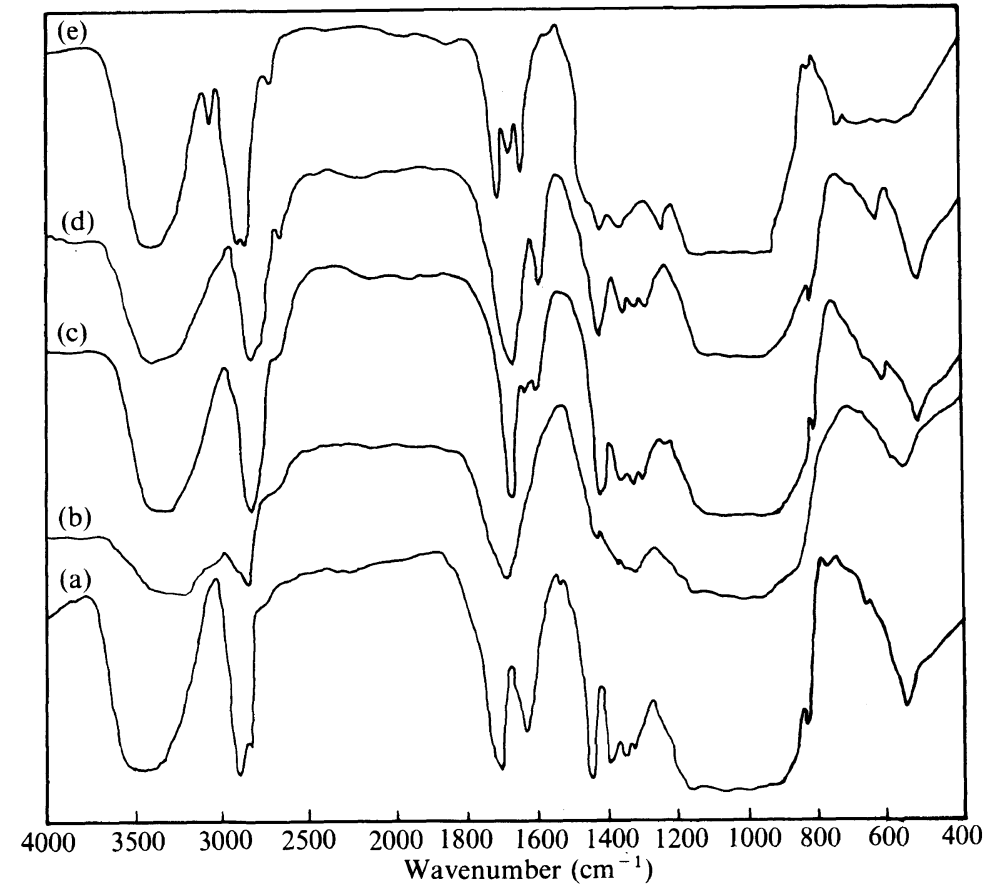

Figure 7. The IR spectrum of polyacrolein obtain by (a) $3 \mathrm{~h}$ irradiation under vacuum at $0^{\circ} \mathrm{C}$, (b) $2 \mathrm{~h}$ irradiation under vacuum at $25^{\circ} \mathrm{C}$, (c) $5 \mathrm{~h}$ irradiation of aqueous solution with $\mathrm{pH}=1.5$ at $25^{\circ} \mathrm{C}$ and in vacuo, (d) $15 \mathrm{~h}$ irradiation of aqueous solution with $\mathrm{pH}=5$ at $25^{\circ} \mathrm{C}$ and in vacuo, and (e) base catalysis with $\mathrm{pH}=9$ at $25^{\circ} \mathrm{C}$. 
ty at higher $\mathrm{pH}$.

\section{Structure of Polyacrolein by IR-Spectra}

The IR spectra of polymers obtained under different polymerization conditions are shown in Figure 7. In the spectra of all the polymer samples studied, the polymer chains contain bonds corresponding to ether, acetal, carbonyl, hydroxide, and unsaturated hydrocarbon groups in various amounts. However, the peaks corresponding to these groups are very close or overlap. Therefore, it is not possible to draw definite conclusions about the changes in the molecular structure, which may show small differences according to the type of polymerization. For example, the broad peak at 800 $1200 \mathrm{~cm}^{-1}$ in all spectra of Figure 7 can be attributed to groups such as $-\mathrm{C}-\mathrm{C}-\mathrm{O}-,-\mathrm{C}-\mathrm{O}-$ $\mathrm{C}-, \mathrm{H}_{2} \mathrm{C}=\mathrm{CH}-$, and $-\mathrm{CH}_{2}$ which cannot be resolved. The aldehyde peak at $1725 \mathrm{~cm}^{-1}$ is observed in each spectrum, with a high relative intensity for radiation-initiated polymers. The peak intensity of the aldehyde group is relatively small in Figure 7e which corresponds to polymers obtained by base catalysis at $\mathrm{pH}$ 9. Therefore, base catalyzed polymers have smaller amounts of free aldehyde groups than radiation-initiated polymers. The peak at $3080 \mathrm{~cm}^{-1}$ in the spectrum of Figure $7 \mathrm{e}$ corresponds to $\mathrm{H}_{2} \mathrm{C}=\mathrm{CH}$ groups and is not observed in spectra of radiation initated polymers. Therefore, the base catalyzed PA contains more vinyl groups than radiation-initiated PA. The $\mathrm{C}=\mathrm{C}$ stretching peaks at 1643 and $1470 \mathrm{~cm}^{-1}$ appear in all spectra except that in Figure $7 \mathrm{~b}$ which is the spectrum of polymer obtained by $2 \mathrm{~h}$ irradiation of monomer in vacuo at $25^{\circ} \mathrm{C}$. These peaks were observed in this polymer also for the irradiation time of $1.5 \mathrm{~h}$. The peaks disppeared with further irradiation. The $-\mathrm{CO}-\mathrm{H}$ vibration peak at $2800 \mathrm{~cm}^{-1}$ exists in all specta shown in Figure 7. The broad peak at $3300-3600 \mathrm{~cm}^{-1}$ in all spectra corresponding to $-\mathrm{O}-\mathrm{H}$ stretching indicates a high content of hydroxyl groups in PA prepared under various con- ditions.

The following additional information was obtained from IR spectra of polymer samples, some of which are not given in Figure 7: (a) For base catalyzed polymers, the relative intensity of the aldehyde peak increased with increase of $\mathrm{pH}$ and polymerization temperature. (b) The relative intensity of aldehyde peaks showed no change with $\mathrm{pH}$ for radiationinitiated polymerization in vacuo at $25^{\circ} \mathrm{C}$, but the intensity of peaks corresponding $-\mathrm{C}=\mathrm{C}$ at $1643 \mathrm{~cm}^{-1}$ decreased with increase of $\mathrm{pH}$. (c) The aldehyde peak intensity is higher for bulk polymerization in vacuo than for polymerization in air. (d) The aldehyde content of polymer samples did not increase for polymerization in an aqueous solution, possibly due to protonation, when compared with polymerization in bulk or in acetone solution.

The possible structural subunits in PA suggested in the literature and also confimed in this work by IR and thermogravimetric analysis are given in Figure 8.

\section{Structural Investigation by Thermal Analysis}

The dehydration of PA was studied by recording weight loss at various temperatures (Figure 9). The change of slope at different temperature ranges corresponds to dehydration of different subunits in Figure 8. Hunter and Forbes ${ }^{14}$ investigated the structure of PA prepared by a redox catalyst using a fractional dehydration method. They showed the dehydration of subunits in the following

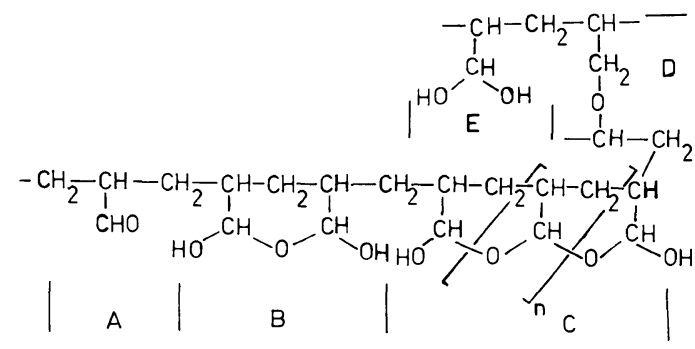

Figure 8. Structural subunits in polyacrolein chain (A) free aldehyde, (B) isolated dihydroxytetrahydropyran rings, (C) ladder structured tetrahydropyran rings, (D) ether bridges, and (E) hydrated aldehyde. 
orders and temperatures: up to $348 \mathrm{~K}$ free water bounded to aldehyde; at $348-378 \mathrm{~K}$ subunit $\mathrm{C}$ in Figure 8; at $378-475 \mathrm{~K}$ subunit $\mathrm{B}$; and at $475-518 \mathrm{~K}$ subunit $\mathrm{A}$ and $\mathrm{E}$. A similar trend in weight decrease was also observed for radiation-initiated polymer as shown in Figure 9. At temperature higher than about $680 \mathrm{~K}$ PA pyrolized completely.

The percentage of each subunit in the polymers obtained under different conditions may not be the same. In order to verify this, the thermograms of PA prepared under various conditions were taken. Some of these thermograms are shown in Figure 10. In most of the thermograms, two broad peaks at 320

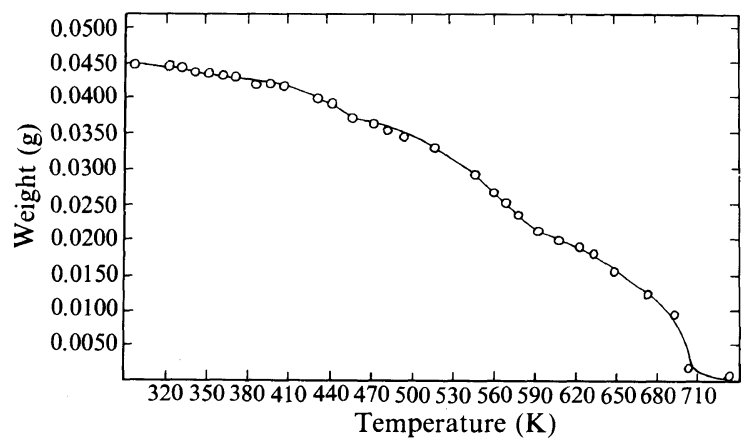

Figure 9. Weight decrease of polyacrolein with increasing temperature.

a

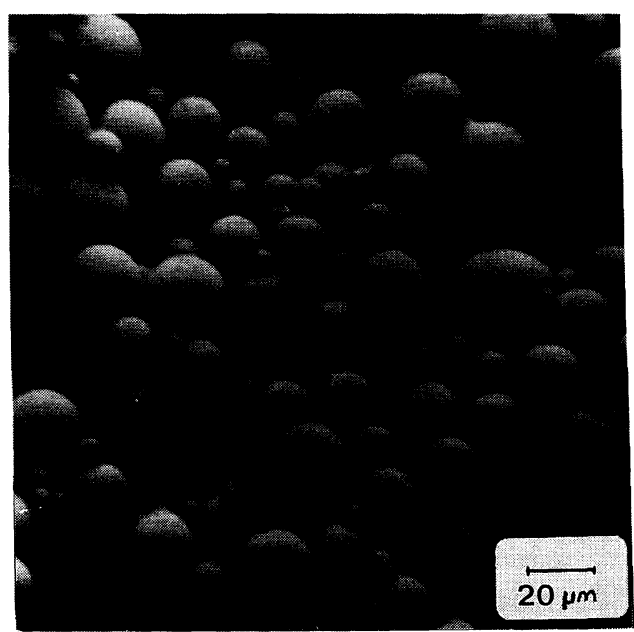

$380 \mathrm{~K}$ and $400-475 \mathrm{~K}$, and a third peak centered at $500 \mathrm{~K}$ were observed. The first peak corresponds to subunit $\mathrm{C}$, the second peak to subunit $\mathrm{B}$, and third peak to the free aldehyde. Radiation-initiated polymers at $25^{\circ} \mathrm{C}$ in vacuo and at $-15^{\circ} \mathrm{C}$ in air (Figures $10 \mathrm{a}$ and $\mathrm{b}$ ) are

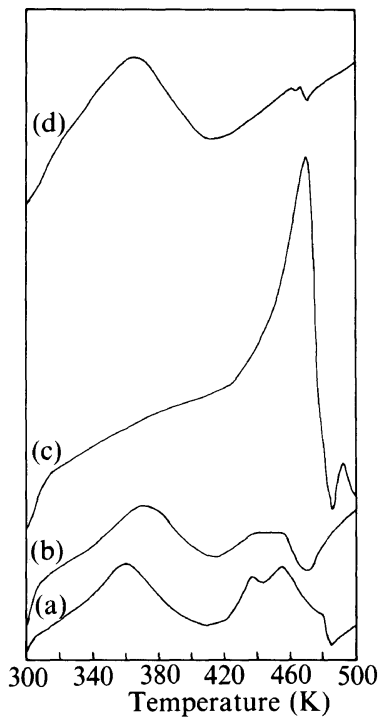

Figure 10. Thermograms of polyacrolein obtain by (a) $44 \mathrm{~h}$ irradiation in air atmosphere at $-15^{\circ} \mathrm{C}$, (b) $2 \mathrm{~h}$ irradiation under vacuum at $25^{\circ} \mathrm{C}$, (c) $37 \mathrm{~h}$ irradiation under vacuum at $-15^{\circ} \mathrm{C}$, and (d) base catalysis with $\mathrm{pH}=11$ at $-30^{\circ} \mathrm{C}$.

b

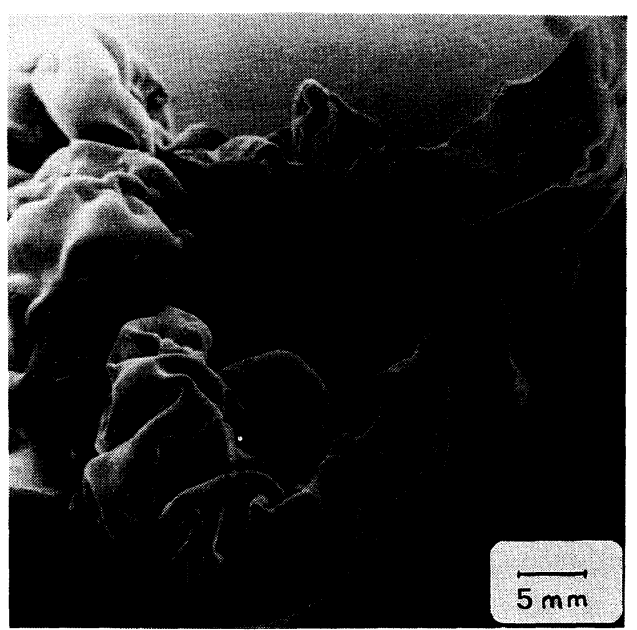

Figure 11a. SEM of polyacrolein $(\times 2000)\left(2 \mathrm{~h}\right.$ irradiation under vacuum at $\left.25^{\circ} \mathrm{C}\right)$.

Figure 11b. SEM of polyacrolein $(\times 50)\left(37 \mathrm{~h}\right.$ irradiation under vacuum at $\left.-15^{\circ} \mathrm{C}\right)$. 


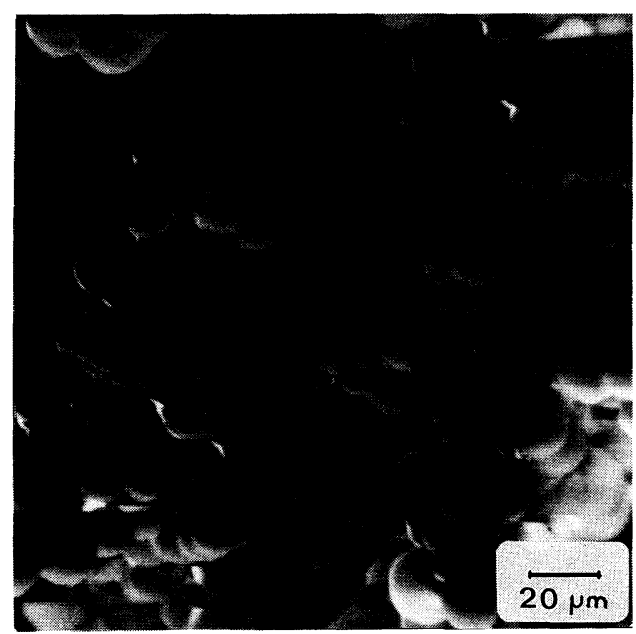

e

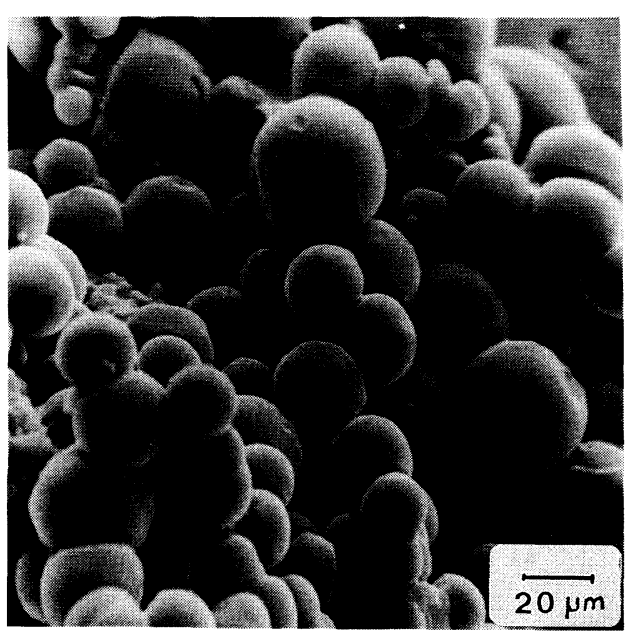

d

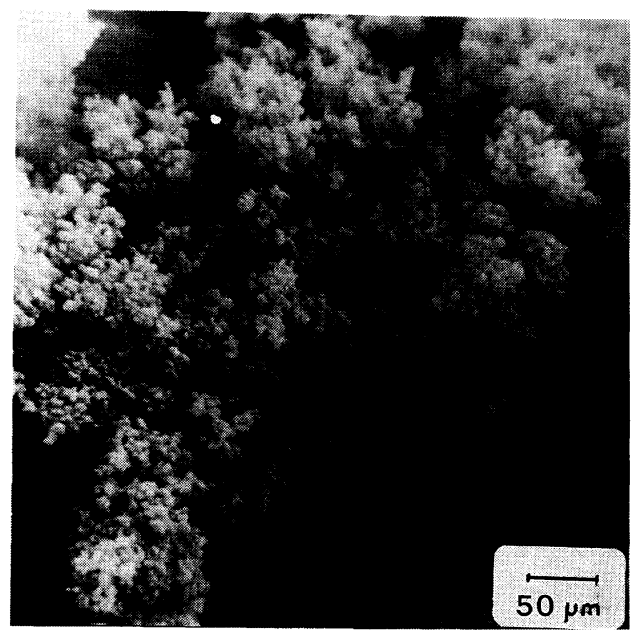

f

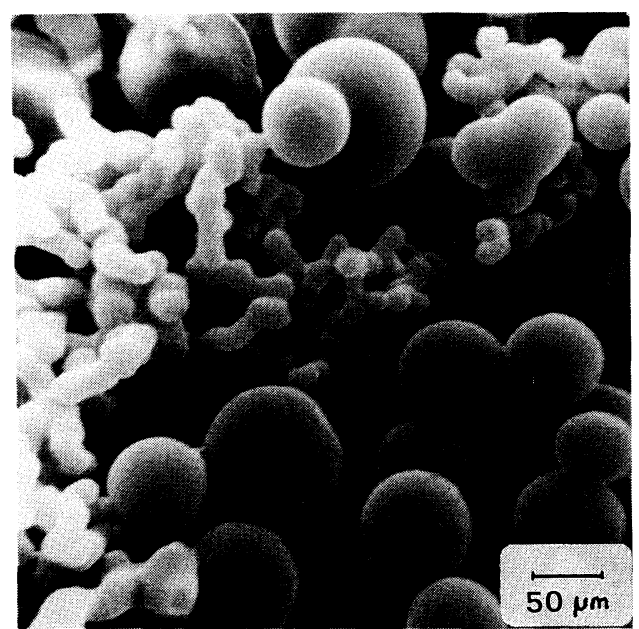

Figure 11c. SEM of polyacrolein $(\times 2000)\left(44 \mathrm{~h}\right.$ irradiation in air atmosphere at $\left.-15^{\circ} \mathrm{C}\right)$.

Figure 11d. SEM of polyacrolein $(\times 5000)(36 \mathrm{~h}$ irradiation of aqueous solution with $\mathrm{pH}=5$, under vacuum at $25^{\circ} \mathrm{C}$ ).

Figure 11e. SEM of polyacrolein $(\times 2000)(84 \mathrm{~h}$ irradiation of aqueous solution with $\mathrm{pH}=7$, under vacuum at $25^{\circ} \mathrm{C}$ ).

Figure 11f. SEM of polyacrolein $(\times 5000)\left(42 \mathrm{~h}\right.$ irradiation of acetone solution under vacuum at $\left.25^{\circ} \mathrm{C}\right)$.

quite similar, and contain subunits $\mathrm{B}$ and $\mathrm{C}$ in addition to free aldehyde. Radiation-initiated polymers at $-15^{\circ} \mathrm{C}$ in vacuo (Figure $10 \mathrm{c}$ ) contain mostly the subunit $\mathrm{B}$, while base catalyzed polymers at $\mathrm{pH} 11$ contain a larger percentage of subunit C (Figure 10d). The largest percentage of free aldehyde is observed in Figure $10 \mathrm{~b}$ for the radiation-initiated polymer at $25^{\circ} \mathrm{C}$ in vacuo.

\section{Microspherical Structure of Polyacrolein}

Scanning electron micrographs (SEM) of PA obtained under various conditions were taken and some are shown in Figures $11 \mathrm{a}-\mathrm{f}$. 
The SEM of PA obtained by $2 \mathrm{~h}$ irradiation at $25^{\circ} \mathrm{C}$ in vacuo is given in Figure 11a. Two types of microspheres with relative diameters of $15-20 \mu \mathrm{m}$ and $1-5 \mu \mathrm{m}$ are observed. When the polymerization temperature decreased to $-15^{\circ} \mathrm{C}$, the product was in a gel form after $5 \mathrm{~h}$ irradiation and SEM (Figure $11 \mathrm{~b})$ shows the polymer to be in a ruptured sheet form. The effect of air is observed in Figure 11c. In this micrograph, the polymer is obtained by $44 \mathrm{~h}$ irradiation at $-15^{\circ} \mathrm{C}$ in air. The microspheres with sizes similar to the ones in Figure 11a, are embedded in the gel domain. The SEM of PA by radiationinitiation from aqueous solution at $\mathrm{pH} 5$ and $\mathrm{pH} 7$ are shown in Figures $11 \mathrm{~d}$ and Figure $11 \mathrm{e}$, respectively. The microspheres at $\mathrm{pH} 5$ are very small, while those at $\mathrm{pH} 7$ have a diameter of $15-30 \mu \mathrm{m}$ and less. Thus, the size of microsphere changes drastically with change of $\mathrm{pH}$. The SEM of radiation-initiated polymer from acetone solution is given in Figure 11f. Two types of microspheres differing in size are observed. The small microspheres are bound to each other in closely formed chains similar to worry beads.

\section{CONCLUSIONS}

Acrolein can readily be polymerized by radiation or base catalysis to give polymers containing vinyl and aldehyde groups in random copolymer form. The largest percentage of subunits in polymer chains is free aldehyde, isolated dihydroxytetrahydropyran rings and fused or ladder structure tetrahydropyran rings. The conditions of polymerization studied in this work and also the works reported to date do not give a selective chain addition reaction of either vinyl or aldehyde groups. The polymerization temperature and irradiation medium has important effects on the resultant product. At lower temperatures, gel type polymer forms when the conversion ex- ceeds about $5 \%$, but at $25^{\circ} \mathrm{C}$, the microspherical structure with a high percentage of free aldehyde content is more favored. The polymerization in aqueous solution gives limited conversion and large microsphere structure only at higher $\mathrm{pH}$ values.

In this work, it is shown that better quality PA with microsphere structure can be obtained by radiation-induced bulk polymerization under suitable conditions. The use of additives and catalysts in polymerization as shown in reported works may contaminate the polymer product and make it less suitable for clinical use.

\section{REFERENCES}

1. R. L. Lipnick, Tetrahedron Lett., 12, 931 (1973).

2. E. Brown, A. Racois, M. Grimaud, J. C. Lecoq, R. Tixien, and M. Corgier, Makromol. Chem., 179, 2887 (1978).

3. S. Margel and A. Rembaum, Macromolecules, 13, 19 (1980).

4. S. Margel, Methods Enzymol., 112, 164 (1985).

5. M. Pines and S. Margel, J. Immunoassay, 7, 97 (1986).

6. R. C. Schulz, K. Meyersen, and W. Kern, Makromol. Chem., 59, 123 (1963).

7. S. Margel, Ind. Eng. Chem. Prod. Res. Rev., 21, 343 (1982).

8. A. Rembaum, M. Chang, G. Richards, and M. Li, $J$. Polym. Sci., Polym. Chem. Ed., 22, 609 (1984).

9. M. Kumakura, M. Suzuki, and I. Kaetsu, J. Collect. Interface Sci., 97, 157 (1984).

10. S. Margel, J. Polym. Sci., Polym. Chem. Ed., 22, 3521 (1984).

11. S. Margel and E. Wiessel, J. Polym. Sci., Polym. Chem. Ed., 22, 145 (1984).

12. M. Kumakura and I. Kaetsu, J. Polym. Sci., Polym. Chem. Ed., 23, 131 (1985).

13. M. Chang, G. Richards, and A. Rembaum, Methods Enzymol., 112, 150 (1985).

14. L. Hunter and J. W. Forbes, J. Polym. Sci., A, 3, 3471 (1965).

15. I. V. Andreeva, V. N. Artemyeva, V. V. Nesterov, and N. V. Kukorkina, J. Polym. Sci., Polym. Chem. Ed., 17, 3415 (1979).

16. M. Chang and A. Rembaum, J. Polym. Sci., Polym. Lett. Ed., 22, 279 (1984). 